\title{
Spica MRI after closed reduction for developmental dysplasia of the hip
}

\author{
Tal Laor
}

Received: 3 March 2011 / Accepted: 14 March 2011 /Published online: 7 May 2011

(C) Springer-Verlag 2011

Sir,

I read with interest the recent technical innovation article entitled "Spica MRI after closed reduction for developmental dysplasia of the hip" [1]. The authors report the use of a short MRI examination immediately following placement of a spica cast to confirm proper reduction. Although not included in the reference list of this recent publication, many points discussed regarding this technique have been described previously [2,3]. After publication in 2000, postoperative limited spica MRI evaluation completely supplanted the use of CT at our institution. The lack of radiation exposure or need for sedation, improved soft tissue delineation, rapid imaging time, ease of scheduling and reduced comprehensive cost supported prompt acceptance of the practice by our orthopedic surgeons.
Hopefully, this current publication reiterating the previously reported findings will further promote the widespread use of this practice.

\section{References}

1. Desai AA, Martus JE, Schoenecker J et al (2011) Spica MRI after closed reduction for developmental dysplasia of the hip. Pediatr Radiol. doi:10.1007/s00247-010-1965-3

2. McNally EG, Tasker A, Benson MK (1997) MRI after operative reduction for developmental dysplasia of the hip. J Bone Joint Surg Br 79:724-726

3. Laor T, Roy DR, Mehlman CT (2000) Limited magnetic resonance imaging examination after surgical reduction of developmental dysplasia of the hip. J Pediatr Orthop 20:572-574

T. Laor $(\triangle)$

Department of Radiology,

Cincinnati Children's Hospital Medical Center,

3333 Burnet Ave,

Cincinnati, OH 45229, USA

e-mail: laor@cchmc.org 